\title{
Práticas educativas de professores e comportamentos infantis, na transição ao primeiro ano do Ensino Fundamental
}

\section{Educative practices of teachers and child behavior, the transition to the first year of elementary school}

\section{Prácticas educativas de maestros y el comportamiento de los niños, la transición al primer año de la escuela primaria}

\author{
Alessandra Turini Bolsoni-Silva* \\ Universidade Estadual Paulista - UNESP, Bauru, São Paulo, Brasil \\ Maria Luiza Mariano** \\ Universidade Estadual Paulista - UNESP, Bauru, São Paulo, Brasil
}

\begin{abstract}
RESUMO
A presente pesquisa tem por objetivos: (a) descrever interações positivas e negativas estabelecidas entre professor e aluno considerando grupo clínico para problema de comportamento e não clínico; (b) descrever repertório comportamental (habilidades sociais e problemas de comportamento) de crianças com e sem classificação clínica para problemas de comportamento conforme TRF, versão professor. Participaram deste estudo 16 professoras que indicaram e avaliaram 32 alunos, sendo 16 com problema de comportamento (PC - grupo clínico) e 16 sem problema de comportamento (sem PC - grupo não clínico). Os alunos com idade de 6 anos estavam matriculados no primeiro ano do Ensino Fundamental. A coleta de dados foi conduzida através da aplicação de três instrumentos: TRF, RE-HSEPr e QRSH-Pr na forma de entrevista com as professoras. Os dados foram categorizados e analisados para comparar os grupos clínico e não clínico (Teste Mann-Whitney). De forma geral, a presente pesquisa encontrou que as professoras exercem práticas diferenciadas entre os alunos que apresentam problemas de comportamento dos que não apresentam, sendo mais habilidosas nas interações com as crianças sem problemas de comportamento e mais agressivas com as que apresentam problemas de comportamento. Discutem-se implicações para intervenções e políticas públicas.
\end{abstract}

Palavras-chaves: interação professor-aluno, práticas educativas, habilidades sociais, problemas de comportamento, ensino fundamental.

\section{ABSTRACT}

The objectives this research are: (a) describing positive interactions established between teacher and student, considering clinical group to behavior problems and non-clinical one; (b) describing behavior repertoire (social skills and behavior problems) of children with and without clinical 
classification to behavior problems, according to TRF, teacher version. The participants this study were 16 female teachers who indicated and evaluated 32 students - 16 of them presented behavior problems (with BP - clinical group), whereas the other 16 did not (without BP - non clinical group). Students aged 6 years were enrolled in the first year of elementary school. Data collection was conducted through the application of three instruments: TRF, RE-HSE-Pr and QRSH-Pr, as an interview with teachers. Data were categorized and analyzed to compare the clinical and nonclinical groups (Mann-Whitney Test). Overall, this research found that female teachers exert different practices among students who have behavior problems that do not show, being more skilled in the interactions with children without behavior problems and more agressive to those with behavioral problems. Implications for interventions and public policies are discussed.

Keywords: teacher-student interaction, educational practices, social skills, behavior problems, elementary education.

\begin{abstract}
RESUMEN
Esta investigación tiene como objetivos: (a) describir las interacciones positivas y negativas que se establecen entre profesor $y$ alumno teniendo en cuenta el grupo clínico para los problemas de conducta y; (b) describir repertorio conductual no clínica (habilidades sociales y problemas de conducta) en niños con y sin clasificación clínica para los problemas de conducta como TRF, versión maestra. El estudio indicó que 16 profesores y 32 estudiantes evaluados, 16 con problemas de conducta (PC - grupo clínico) y 16 sin problemas de conducta (sin PC - grupo no clínico). Los alumnos de 6 años estaban matriculados en el 1er año de la escuela primaria. La recolección de datos se llevó a cabo mediante la aplicación de tres instrumentos: TRF, RE-HSE-Pr y QRSH-Pr, como una entrevista con los maestros. Los datos se clasificaron y analizaron para comparar los grupos clínicos y no clínicos (Prueba Mann-Whitney). En general, esta investigación encontró que los profesores ejercen diferentes prácticas entre los estudiantes que tienen problemas de conducta que no muestran, por ser más experto en las interacciones con los niños sin problemas de conducta y más agresivo para aquellos con problemas de conducta. Las implicaciones para las intervenciones y las políticas públicas son discutidas.
\end{abstract}

Palabras clave: interacción profesor-alumno, prácticas educativas, habilidades sociales, problemas de conducta, educación primaria.

\title{
1 Introdução
}

O objeto de estudo desta pesquisa é a interação da prática educativa do professor com 0 aluno ingressante no primeiro do ensino Fundamental. Marturano (2008) afirma que a entrada no primeiro ano é conhecida como marco de transição na vida da criança e de acordo com a Lei no 11.274, de 06/02/2006 (2006) está acontecendo mais cedo. A autora ainda coloca, no plano das interações sociais, que há exigência de negociar interações não só com crianças da mesma idade, como também com as crianças mais velhas em seu ciclo, sem contar que, no plano acadêmico, a criança se depara com o papel de aluno com uma extensa agenda de atribuições e tarefas. Pereira, Marturano, Gardinal-Pizato e Fontaine (2011) encontraram 
que quando a criança frequenta a pré-escola ela tem melhores indicadores de desempenho acadêmico e habilidades sociais. BolsoniSilva, Marturano e Freiria (2010) também preocupadas em avaliar a transição da pré-escola para o ensino fundamental, em um estudo longitudinal, avaliaram crianças com e sem problemas de comportamento, do ponto de vista de mães/cuidadoras e encontraram que as crianças mais habilidosas na pré-escola continuavam mais habilidadosas no ensino fundamental; já os indicadores de problemas tenderam a diminuir na segunda avaliação, mas o grupo clínico manteve-se com mais problemas. Considerando esses três estudos, tais achados indicam que frequentar o ensino fundamental exige da criança competências que o ensino infantil pode ajudar a promover, favorecendo o desempenho acadêmico e interpessoal. É notória a relação entre problemas de comportamento e dificuldades de aprendizagem (Bandeira, Rocha, Souza, Del Prette \& Del Prette, 2006), sendo assim, o estudo dos problemas de comportamento pode auxiliar a reduzir também dificuldades de aprendizagem.

Conforme Del Prette e Del Prette (2001), as interações sociais sempre foram objeto de estudo e de pesquisa para várias abordagens psicológicas e, dessa forma, essas relações têm sido investigadas em diversos contextos há bastante tempo, justificando o interesse na descrição destes fenômenos. Uma forma de estudar interações sociais é valer-se de conhecimentos acumulados na área de habilidades sociais.

A expressão habilidades sociais refere-se a um campo de pesquisa e aplicação do conhecimento psicológico destinado ao desempenho das pessoas nas interações sociais em diversos contextos (Del Prette \& Del Prette, 1999, 2001). Bolsoni-Silva (2002) e Bolsoni-Silva e Carrara (2010) consideram as habilidades sociais como comportamentos, emitidos na interação social que parecem colaborar na resolução de problemas, na redução de conflitos e na promoção e/ ou manutenção de interações sociais satisfatórias e agradáveis. A partir de achados da literatura parece haver associação entro o uso de práticas negativas do professor e a ocorrência de comportamentos problema nos alunos, bem como as práticas positivas estão associadas à emissão de comportamentos socialmente habilidosos de alunos (Castro \& Bolsoni-Silva, 2008; Baker, Grant, \& Morlock, 2008). As interações entre as pessoas podem ser positivas ou negativas, do ponto de vista do professor (práticas positivas e práticas negativas) e do ponto de vista do aluno (problemas de comportamento e habilidades sociais), os quais se influenciam mutuamente. Parece que as práticas negativas do professor (por exemplo gritar, castigar) estimulam comportamentos problema em seus alunos e, ao contrário, as práticas positivas (por exemplo conversar, ser afetuoso e atencioso) podem favorecer a promoção de 
habilidades sociais. Os problemas de comportamento, de acordo com Achenbach e Rescorla (2001), podem ser classificados como externalizantes (tais como desobediência e agressividade) e internalizantes (como tristeza e ansiedade).

Acredita-se que as práticas educativas positivas do professor podem ser entendidas como interações que promovem o desenvolvimento infantil e podem ser organizadas em categorias, tais como comunicação (Fonseca, 2012; Howie, Lukacs, Pastor, Reuben, \& Mendo-la, 2010; Uysal \& Ergenekon, 2010), estabelecimento de regras (Gomes, 2003), treino em resolução de problemas (Allen \& Blackston, 2003), valorização de comportamentos espe-rados (Barnett, Bauer, Ehrhardt, Lentz, \& Stdlar, 1996), oferecimento de suporte (Greene \& Ollendick, 1993), manejo positivo (Webster-Stratton, Reid, \& Stoolmiller, 2008), valer-se do afeto (Baker, Grant, \& Morlock, 2008; Kullok, 2002; Ribeiro, 2010), envolver a família (Webster-Stratton et al., 2008), estimular a criatividade e interação com colegas (Oliveira \& Wechsler, 2002).

Adicionalmente, Bolsoni-Silva, Mariano, Loureiro e Bonarccorsi (2013) encontraram que as professoras utilizam de práticas negativas mais frequentemente com as crianças com problemas de comportamento, sugerindo que essas estratégias de estabelecer limites, ao invés de reduzir os problemas, os aumentam de frequência. De acordo com esse estudo, espera-se que o professor aprenda a comunicarse, ser afetivo e estabelecer limites, sobretudo com as crianças com problemas de comportamento, ao contrário do uso frequente de práticas negativas, que acaba estimulando a agressividade nas crianças (Bolsoni-Silva et al., 2013).

Poucos são os estudos que conseguem descrever múltiplas variáveis de práticas positivas e negativas com professores, especialmente na interação com habilidades sociais ou problemas de comportamento infantis. Castro e Bolsoni-Silva (2008) encontraram ao analisar filmagens de interações professora-alunos que quando as professoras eram comunicativas e afetivas com seus alunos, os mesmos reagiam também com afeto e comunicação e, ao contrário, quando elas usavam práticas negativas (por exemplo gritos, castigos), as crianças comportavam-se de maneira agressiva, suportando a ideia de que professores e alunos influenciam-se mutuamente nas interações estabelecidas. Baker, Grant e Morlock (2008) avaliaram a relação professor-aluno, especificamente o grau de proximidade e o conflito existente; os resultados sugeriram que a qualidade nessa relação, ou seja, a cordialidade e fornecer confiança ao aluno, ajuda no ajustamento escolar. Fonseca (2012) encontrou que as professoras são mais comunicativas e afetuosas com as crianças sem problemas de comportamento, exercendo, assim, práticas diferenciadas entre os alunos com e sem dificuldades comportamentais. Bolsoni-Silva et al. (2013) encontraram que as práticas negativas e os comportamentos 
problema dos alunos eram estatisticamente maiores no grupo clínico para problemas de comportamento, quando comparados a crianças não clínicas. Outro dado importante investigado pelas autoras Bolsoni-Silva et al. (2013) foi que tanto meninas como meninos apresentavam habilidades sociais, mas as meninas apresentaram mais comportamentos habilidosos e os meninos mais problemas de comportamento.

Ainda que a literatura (Fonseca, 2012; Howie, Lukacs, Pastor, Reuben, \& Mendo-la, 2010; Uysal \& Ergenekon, 2010) sinalize a importância da prática do professor para o desenvolvimento do aluno, são poucos os estudos preocupados em avaliar as suas habilidades sociais na influência mútua com o comportamento das crianças, isto é, identificar o que os professores fazem e como as crianças reagem, de modo a destacar a bidirecionalidade dessas relações interpessoais. Também poucos estudos (Bolsoni-Silva et al., 2013) utilizam instrumentos diagnósticos na diferenciação de grupos clinico e não clínico, além de utilizar amostra reduzida. Portanto, o estudo das interações professor-aluno, com suas mútuas influências, na transição para o ensino fundamental parece ser importante de forma a esclarecer facilidades e dificuldades existentes, sobretudo com as crianças com problemas de comportamento, permitindo a elaboração de intervenções eficazes na promoção do desenvolvimento da criança.

Diante dessas considerações, e a partir de avaliações dos professores, a presente pesquisa tem por objetivos: (a) descrever e comparar interações positivas e negativas estabelecidas entre professor e aluno, considerando grupo clínico para problema de comportamento e não clínico; (b) descrever e comparar repertório comportamental (habilidades sociais e problemas de comportamento) de crianças com e sem classificação clínica para problemas de comportamento conforme TRF.

\section{Método}

\section{Participantes}

Participaram deste estudo 16 professoras que indicaram e avaliaram 32 alunos, sendo 16 com problema de comportamento (clínico) e $16 \mathrm{sem}$ problema de comportamento (não clínico). Os alunos com idade de seis anos (Média $=6,5$ e Desvio-Padrão $=2,3$ ) estavam matriculados no primeiro do Ensino Fundamental em dez escolas municipais de Ensino Fundamental (EMEFs), distribuídas geograficamente em lugares centrais e periféricos de uma cidade no Centro Oeste do Estado de São Paulo e com aproximadamente 360 mil habitantes. A idade das professoras variou de 23 a 50 
(média de 33,56, desvio padrão de 2,50 ) e todas tinham formação em Pedagogia. Trata-se de um estudo comparativo que usou uma amostra de conveniência.

A amostra clínica de crianças apresentou a seguinte classificação de acordo com o Inventário dos comportamentos de crianças e adolescentes entre 6 e 18 anos (Teacher's Report Form - TRF): sete crianças apresentavam problemas na escala de externalizantes e total de problemas, três casos pontuaram nas três escalas (internalizantes, externalizantes e total de problemas), duas crianças tinham apenas problemas externalizantes, um caso era limítrofe em externalizante e em total de problemas e três crianças apresentavam problemas externalizantes e eram limítrofes em total de problemas. Por outro lado, o Grupo não clínico não se enquadrou em nenhuma escala do TRF.

A pesquisa foi realizada de acordo com os critérios estabelecidos pelo Conselho Nacional de Saúde, com os cuidados éticos nas pesquisas envolvendo seres humanos, submetida ao Comitê de Ética da Faculdade de Ciências, aprovado sob o n 2567/46/01/09.

\section{Percurso amostral e critérios de seleção}

Seguindo os critérios de seleção, os alunos deveriam estar cursando o primeiro ano do Ensino Fundamental e com idade de seis anos. Os alunos pertencentes ao grupo clínico deveriam atingir o escore de clínico ou limítrofe no TRF (6-18) em ao menos uma das três escalas (internalização, externalização, total). Enquanto que o grupo considerado não clínico não poderia atingir nenhum indicativo de escore clínico nas escalas do TRF.

Quanto aos critérios de seleção das professoras, essas deveriam ser efetivas, dar aulas no primeiro ano. Foram entrevistadas 20 professoras em que indicaram 40 alunos (20 com PC e $20 \mathrm{sem}$ PC), mas de acordo com os critérios de seleção foram excluídos 8 participantes, sendo 4 alunos que não tiveram sua confirmação no TRF e, assim, respectivamente, seus pares não clínicos e seus professores também foram excluídos.

\section{Instrumentos}

Roteiro de entrevista de habilidades sociais educativas para professores (RE-HSE-Pr-Adaptação de Bolsoni-Silva, \& Loureiro, 2011). O objetivo do instrumento é o de descrever interações estabelecidas entre professor e aluno a partir de 66 perguntas que podem ser organizadas em categorias de HSE-Pr: Comunicação (conversa, faz perguntas, faz perguntas sobre sexualidade); Expressão de Sentimentos e Enfrentamento (expressa sentimentos positivos, negativos, opiniões) e Estabelecimento de Limites 
(identifica comportamento apropriado, identifica comportamento inapropriado, relata estabelecer limites, cumpre promessa, admite erros). Para cada uma dessas categorias de HSE-Pr é perguntado como a criança responde a elas, por exemplo a primeira pergunta do instrumento é: "Você conversa com seu aluno?", se o professor responder que sim, então é perguntada a frequência com que ele conversa. A próxima pergunta relacionada diz respeito aos momentos em que a conversa com o aluno ocorre, que pode ser quando a criança tem interesse e faz uma pergunta ou pode ser quando a criança comporta-se de forma que o professor desaprova. Para finalizar a categoria conversar, então é perguntado "nesses momentos em que você conversa com seu aluno, como ele reage?", cuja resposta pode ser a de que o aluno concorda com o professor e que promete comportar-se bem ou pode ser que o professor diga que nesses momentos a criança xinga ou sai batendo porta. Portanto o instrumento descreve sempre o comportamento do professor na interação com o comportamento do aluno e vice-versa. Essas informações são organizadas em categorias: habilidades sociais educativas (práticas positivas), práticas negativas, habilidades sociais infantis e comportamentos problema da criança. A soma das práticas positivas e habilidades sociais das crianças configuram o Total Positivo. A soma de práticas negativas e problemas de comportamento permitem obter o escore de Total Negativo. O índice de consistência interna do instrumento foi de 0,846 , o total positivo teve alfa de 0,827 e o total negativo de 0,646.

Questionário de respostas socialmente habilidosas, versão para professores (QRSH-Pr de Bolsoni-Silva, Loureiro, \& Marturano (2011). Esse instrumento contém 24 questões do tipo likert em que o respondente deve escolher entre três, uma alternativa que mais se encaixa aos comportamentos de seu aluno. A validação encontrou satisfatórias validades de construto, discriminativa e preditiva. $O$ instrumento avalia habilidades sociais como fazer pedidos, comunicar-se, expressar frustrações e expressar opiniões. A consistência interna do instrumento é de 0,930.

Inventário dos comportamentos de crianças e adolescentes entre 6 e 18 anos - Relatório para professores (Teacher's Report Form TRF - 6-18, Achenbach \& Rescorla, 2001). Contém 113 perguntas sobre problemas de comportamentos dos alunos. Os escores nos itens individuais são combinados para identificar padrões gerais de comportamento: externalizante, internalizante e total de problemas que são classificados em clínico, não clínicos e limítrofes. Os escores limítrofes, como sugestão do próprio manual, foram considerados como clínicos. $O$ instrumento avalia com que frequência às crianças são agressivas, desobedientes, tristes ou ansiosas, por exemplo. O índice de consistência para a escala toda é de 0,92, para externalização é de 0,88 e em internalização de 0,80. 


\section{Procedimento de coleta de dados}

Os passos de coleta de dados consistiram em: (a) visita à Secretaria Municipal de Educação obtendo sua autorização para efetuar a pesquisas nas EMEFs; (b) visita às escolas com apresentação ao Diretor da Unidade Escolar com resumo do projeto e convite aos professores para participarem da pesquisa, momento em que foram agendadas as entrevistas; (c) O professor era solicitado a indicar uma criança que considerasse apresentar problemas de comportamento em sala de aula e uma criança que era habilidosa; (d) entrevista agendada na escola, onde foram explicados os objetivos do trabalho, com pedido do consentimento e assinatura do Termo de Consentimento Livre e Esclarecido, por pais e professores, (e) realização da entrevista a partir do instrumento RE-HSE-Pr e aplicação do QRSH-Pr e do TRF 6-18. O tempo médio da entrevista com cada professor foi de 40 minutos.

\section{Procedimento de análise de dados}

Para obter as categorias do RE-HSE-Pr foram utilizadas as indicadas na versão de pais (RE-HSE-P, Bolsoni-Silva \& Loureiro, 2011) e incluídas novas a partir de análise de conteúdo (Bardin, 2009) realizada a partir da leitura das transcrições das entrevistas com os professores previamente gravadas, como por exemplo interações próprias da interação escolar, como enviar bilhete para os pais da criança. Em seguida, foi realizada a categorização a partir do instrumento RE-HSE-Pr e, por fim, foi feita a comparação entre os grupos (clínico e não clínico) e com nível de significância menor ou igual a 0,05 (Teste Mann-Whitney). O teste não paramétrico é o indicado para a análise da presente amostra devido à ausência do pressuposto de normalidade dos dados, uma vez que antes do início do tratamento dos dados foi verificado, pelo teste KolmorogovSmirnov, que os não estavam na curva normal. Assim, utilizou-se as medianas na comparação entre os grupos clínico e não clínico. Os dados obtidos a partir do QRSH-Pr também foram tratados estatisticamente de forma a comparar os grupos de alunos clínico e não clínico (Teste Mann-Whitney). Os resultados são apresentados na forma de figuras e tabelas. Os resultados do RE-HSE-Pr foram exportadas para a planilha do software SPSS (versão 21), o que permitiu obter medianas que foram utilizadas na elaboração de Figuras e tabelas. Foram considerados os resultados com nível de significância menor ou igual a 0,05.

\section{Resultados}


A seção de resultados apresenta a descrição das interações professoras-alunos, a partir do relato das professoras, no que se refere ao total de categorias do RE-HSE-Pr e Comunicação e Expressão de Afeto (Figura 1), Enfrentamento - Expressão de Sentimento negativo e opiniões e Estabelecimento de Limites (Figura 2).

Figura 1

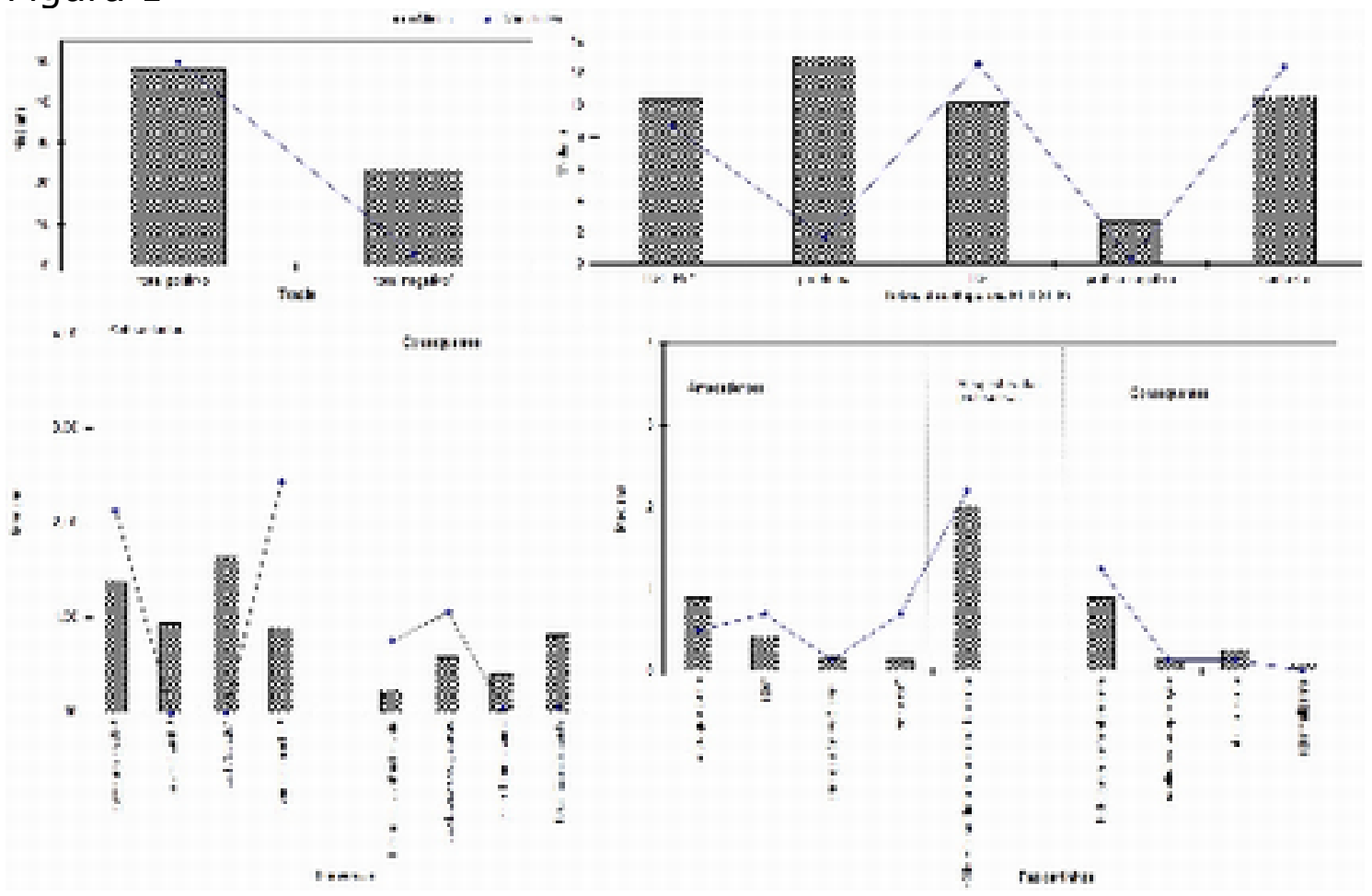

Figura 1. Totais de categoria e Totais Gerais RE-HSE-Pr. Categorias do RE-HSE-Pr relacionadas às HSE-Pr de Comunicação e de Expressar afeto. *Itens com diferença estatisticamente significativa da comparação das medianas dos grupos.

Conforme a Figura 1, referente à somatória de todas as respostas apresentadas pelas professoras, o grupo não clínico apresenta frequência alta de práticas positivas (HSE-Pr) e variáveis de contexto e as crianças também apresentam habilidades sociais, por outro lado, as práticas negativas das professoras e o problema de comportamento apresentam frequência baixa para esse grupo. Notase que o Total Negativo diferenciou o grupo clínico e não clínico ( média do grupo clínico $=23,5 ;$ média do grupo não clínico $=3 ; p$ $=0,00)$. Adicionalmente 0 aluno clínico apresenta comportamentos problema, no caso queixas relatadas de comportamentos indesejados na escola, com maior frequência que o grupo não clínico (média grupo clínico $=12,5$; mediana grupo não clínico $=1 ; p=0,000$ ). Adicionalmente, com o grupo clínico as professoras utilizam mais 
frequentemente habilidades sociais educativas do que com o grupo não clínico (mediana grupo clínico $=10,5$; mediana grupo não clínico $=7 ; p=0,051$ ). Entretanto as habilidades sociais infantis e as variáveis de contexto, que refletem a variabilidade de interações sociais estabelecidas entre professor e aluno, não diferenciaram os grupos.

A seguir, descrevem-se os itens da categoria ampla de habilidades sociais educativas, denominada Conversar e Fazer Carinho, também na Figura 1. As análises da categoria Comunicação do RE-HSEPr mostra que o grupo clínico apresenta, com mais frequência, o conversar diante de concepção de certo e errado (mediana grupo clínico $=2,0$; mediana grupo não clínico $=0,00$ ) e comportamentos externalizantes (mediana grupo clínico $=0,94$; mediana grupo não clínico $=0,00)$. O grupo não clínico, com mais frequência, conversam sobre diversos assuntos (mediana grupo clínico $=0,5$; mediana grupo não clínico $=2,0$ ) e em diferentes momentos do dia (mediana grupo clínico 1,5 ; mediana grupo não clínico $=2,0$ ). As respostas dos alunos, nessas interações sociais, não diferenciaram os grupos, ainda que haja algumas tendências. No grupo não clínico, as respostas classificadas como habilidoso cooperativo e de enfrentamento (aceita opiniões, cumpre as regras, reage bem) ocorrem com maior frequencia, e respostas de problemas comportamentais com frequência proxima a zero. No grupo clínico, as crianças, segundo os relatos de suas professoras, emitem mais comportamentos considerados como problema, no caso externalizantes (não aceitam a opinião do professor, não obedecem às regras, olham outra situação) e, com menor frequencia, comportamentos socialmente habilidosos. Quanto ao afeto os grupos pouco se diferenciam, mas - grupo não clínico relata ser mais afetuoso na categoria contexto ( mediana grupo clínico $=0,12$; mediana grupo não clínico $=0,69$ ), ou seja, em uma diversidade de situações. Os resultados mostram que ambos os grupos são habilidosos quanto a expressão de afeto, sejam as respostas das professoras, sejam as dos alunos. A seguir, descrevem-se os itens da categoria denominada Expressividade de Sentimento e Enfrentamento apresenta a expressão de opiniões e de sentimento negativo.

Figura 2 


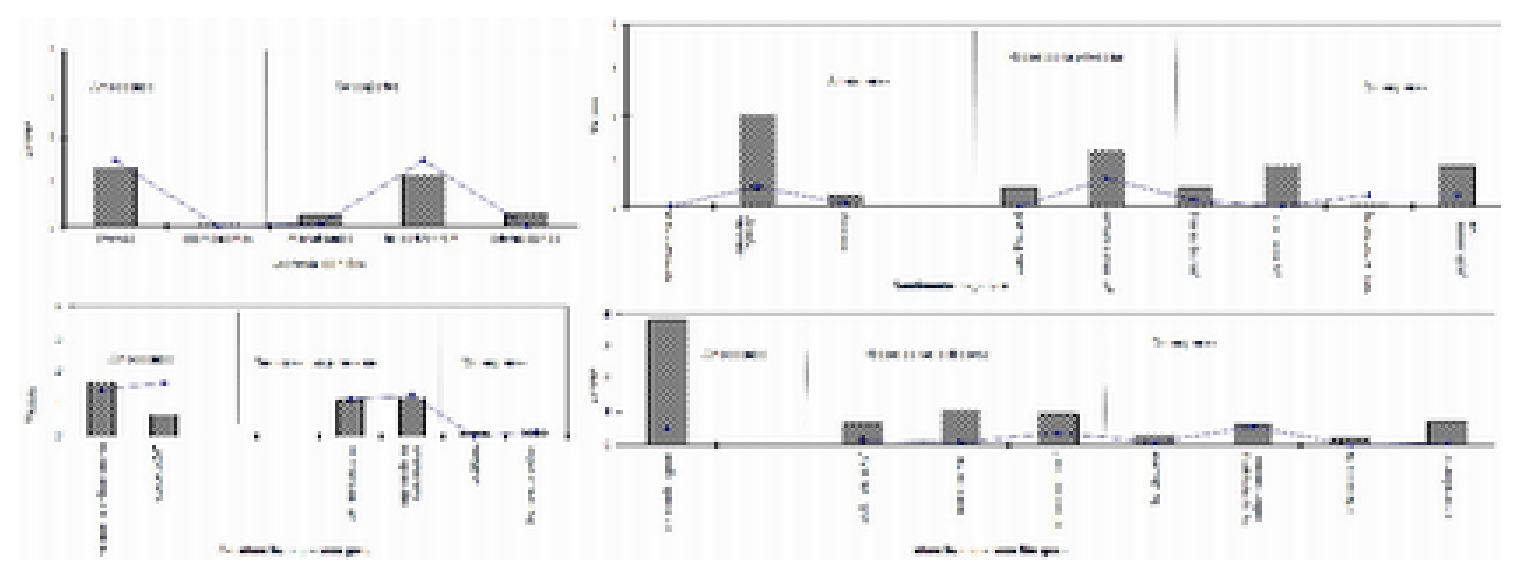

Figura 2 - Categorias do RE-HSE-Pr relacionadas a Enfrentamento - Expressão de Sentimento negativo e opiniões e Estabelecimento de Limites.

*Itens com diferença estatisticamente significativa da comparação das medianas dos grupos.

A Figura 2 traz quatro categorias relacionadas a Estabelecer Limites (Expressar opiniões, Expressar sentimentos negativos, Identificar e consequenciar comportamentos que o professor gosta e que não gosta). A prática educativa de expressar opiniões não diferenciou os grupos clínico e não clínico, os resultados indicam que as professoras expressam opiniões sobretudo em diversos momentos do dia e, as crianças, na maior parte das vezes, incentivam as professoras, comportando-se de forma habilidosa.

A prática de expressar sentimentos negativos das professoras está diretamente relacionada ao comportamento emitido pelo aluno, sobretudo àquele que implica em estabelecimento de limites. Destaca-se que as professoras do grupo clínico, com frequência maior, expressam sentimentos negativos quando as crianças descuidam do ambiente, deixando-o desorganizado, bagunçado (mediana grupo clínico= 2,3; mediana grupo não clínico=0,4). Diante desses comportamentos das crianças, as professoras quando respondem para as crianças clínicas tendem a usar as práticas negativas ativas, como gritar, castigar (mediana grupo clínico= 0,41 ; mediana grupo não clínico=0,0). Por outro lado quando respondem para as crianças não clínicas elas, sobretudo, utilizamse da comunicação (mediana grupo clínico $=1,0$; mediana grupo não clínico $=0,0)$. As respostas dos alunos, nessas situações, são bem diferentes entre os grupos, sendo que no grupo clínico destacam os problemas de comportamentos, externalizantes (mediana do grupo clínico $=0,91$; para o grupo não clínico $=0,0)$ e internalizantes ( mediana do grupo clínico $=0,41$; para o grupo não clínico $=0,13$ ) e, no não clínico, os de habilidades sociais (mediana do grupo clínico=1,0; para o grupo não clínico=0,0). 
As professoras de ambos os grupos identificam comportamentos que gostam em seus alunos, mas ao responderem para o grupo não clínico, identificam maior frequência do comportamento de cooperar (mediana do grupo clínico $=0,65$; para o grupo não clínico $=0,63$ ). As professoras incentivam os comportamentos dos alunos, conversando e sendo afetivas.

Sobretudo as professoras do grupo clínico identificam comportamentos de agressividade e desobediência como comportamentos que não gostam (mediana do grupo clínico = 3,82; para o grupo não clínico $=0,5$ ), momento em que tendem a sentirem-se mal (mediana do grupo clínico $=1,06$; para o grupo não clínico $=0,06$ ) e usarem ou práticas negativas de educação ( mediana do grupo clínico $=0,65$; para o grupo não clínico $=0,13$ ) ou tentam comunicarem-se para estabelecer limites (mediana do grupo clínico $=0,94$; para o grupo não clínico $=0,38$ ). As crianças de ambos grupos obedecem em parte das vezes, mas as do grupo clínico continuam agressivas nesses momentos (mediana do grupo clínico $=0,71$; para o grupo não clínico $=0,06$ ). A seguir, encontra-se na Tabela 1 a análise entre os grupos do relato dirigido do Questionário de Respostas Socialmente Habilidosa versão para professores (QRSH$\operatorname{Pr})$.

\section{Tabela1}

Comparação entre os grupos clínico e não clínico para as habilidades sociais infantis a partir do QRSH-Pr.

\begin{tabular}{|c|c|c|c|}
\hline QRSH-PR* & Clínico & $\begin{array}{c}\text { Não } \\
\text { clinico }\end{array}$ & $p^{* * *}$ \\
\hline \multicolumn{4}{|c|}{$M D$} \\
\hline \multicolumn{4}{|c|}{$\begin{array}{c}\text { Fator } 1- \\
\text { Sociabilidade e Expressividade emocional }\end{array}$} \\
\hline Faz amigos & 2 & 2 & 0,036 \\
\hline $\begin{array}{l}\text { Expressa frustração e desagrado } \\
\text { de forma adequada }\end{array}$ & 1 & 2 & 0,001 \\
\hline Expressa direitos & 1 & 2 & 0,000 \\
\hline Usualmente está de bom humor & 1,5 & 2 & 0,001 \\
\hline \multicolumn{4}{|c|}{ Fator 2 - Iniciativa social } \\
\hline Presta ajuda & 2 & 2 & 0,017 \\
\hline Participa de temas de discussão & 1,5 & 2 & 0,011 \\
\hline Escore total do QRSH-PR & 35 & 44 & 0,000 \\
\hline
\end{tabular}

"Questionário de Respostas Socialmente Habilidosas - Versão Professores.

$" \bar{p}<0,05$.

Na Tabela 1 apresentam-se dados obtidos do questionário de respostas socialmente habilidosas para professores. Os itens de habilidades sociais do Fator 1 mais frequentes para o grupo não clínico são: expressa frustração e desagrado de forma habilidosa e 
usualmente está de bom humor. No Fator 2 os itens de destaque, mais frequentes para o grupo não clínico, são: iniciativa social prestar ajuda, participa de temas de discussão e participar em contexto escolar. O escore total diferenciou o grupo clínico e não clínico, mostrando que as crianças não clínicas apresentam mais respostas consideradas como habilidosas.

\section{Discussão}

O presente estudo buscou descrever interações positivas e negativas estabelecidas entre professor e aluno considerando grupo clínico para problema de comportamento e não clínico. Um segundo objetivo foi o de descrever repertório comportamental (habilidades sociais e problemas de comportamento) de crianças com e sem classificação clínica para problemas de comportamento conforme TRF, versão professor. De maneira geral, nota-se, segundo as avaliações das professoras, que as crianças do grupo não clínico foram mais habilidosas, seja nos momentos de interação positiva com a professora, seja quando estabelecem limites. Destaca-se que as mesmas professoras relataram se comportar de maneira diferente quando se trata de crianças com problemas de comportamento e sem problemas, confirmando a literatura (Bolsoni-Silva et al., 2013; Fonseca, 2012).

As práticas educativas positivas, mensuradas pelas habilidades sociais educativas e variáveis de contexto, foram mais frequentes nas interações sociais com as crianças não clínicas, o que parece concordar com os achados de diversos autores (Kullok, 2002; Fonseca, 2012; Howie, Lukacs, Pastor, Reuben, \& Mendo-la, 2010; Uysal \& Ergenekon, 2010). Práticas educativas positivas também estão presentes no grupo clínico, apontando para recursos de professores na interação com os alunos que podem ser aproveitados em intervenções com a finalidade de promover melhores interações sociais, reiterando pesquisas anteriormente conduzidas, como as de Fonseca (2012) e de Bolsoni-Silva et al. (2013). As crianças no ensino fundamental podem encontrar mais ou menos facilidade de enfrentamento das tarefas exigidas (Marturano, 2008), sendo que 0 repertório inicial de habilidades sociais (Bolsoni-Silva, Marturano \& Freiria, 2010), o fato de terem frequentado previamente a pré-escola (Pereira et al., 2011), os indicadores de problemas de comportamento (Bolsoni-Silva et al., 2013) podem interferir na forma como os professores vão interagir com elas. Com base nos achados da presente pesquisa, conclui-se que se o professor for capaz de manter a calma, dar atenção, carinho e limites contingentes aos comportamentos de todo os alunos, é possível que consigam criar condições de ensino que favoreçam maior engajamento e 
aprendizagem dos alunos. Se os professores dessem atenção às crianças quando elas fossem habilidosas, ou que as ajudasse a resolver conflitos na interação com outras crianças ou mesmo de natureza acadêmica, é possível que elas tivessem baixos escores de problemas de comportamento, os quais, por sua vez, prejudicam o processo ensino-aprendizagem (Bandeira et al., 2006).

A prática educativa mais utilizada pelas professoras foi a da comunicação, que parece não ter produzido os efeitos esperados, no que se refere a ensinar os limites necessários, nos comportamentos das crianças pertencentes ao grupo clínico, o que contraria, afirmações de autores como Howie, Lukacs, Pastor, Reuben e Mendola (2010). Uma hipótese é a de que a qualidade do comunicarse estivesse prejudicando as interações, uma vez que parece contingente a comportamentos considerados como problemas pelas professoras (concepções de certo/errado) e não a temas diversos ou pessoais, mais frequentes no grupo não clínico. Assim, tais conversas ainda que sejam bons recursos das professoras para estabelecer limites, o fato de conversarem, sobretudo nesses momentos, ou seja, para estabelecer limites, pode parecer para a criança uma bronca ou sermão, prejudicando a qualidade da comunicação, favorecendo com que a criança continue agressiva, o que realmente parece acontecer, pois, nessas interações sociais, as crianças do grupo clínico tendem a reagir às conversas das professoras com agressividade.

As professoras ao interagir com os grupos com e sem problemas de comportamento foram capazes de demonstrar afeto e carinho aos seus alunos. Castro e Bolsoni-Silva (2008) também notaram quando as professoras eram afetuosas, seus alunos também o eram. Esses modelos de interação positiva podem melhorar os comportamentos dos alunos que podem conseguir atenção e ter estratégias mais eficazes de resolução de problemas, o que parece reiterar outros estudos (Baker, Grant, \& Morlock, 2008; Kullok, 2002; Ribeiro, 2010).

Quanto às práticas negativas, no grupo não clínico ocorriam raramente, replicando achados de Bolsoni-Silva et al. (2013). Já no Grupo clínico, a prática negativa mostrou-se mais frequente que no grupo não clínico. As práticas negativas foram apresentadas para o grupo clínico de forma ativa (por exemplo, dar broncas e ou castigo) e passiva (não falar nada); essas ações ocorreram após o comportamento agressivo e de desobediência dos alunos e as respostas das professoras foram agressão verbal. Tal achado, de acordo com Bolsoni-Silva e Carrara (2010), destacam que os adultos podem recorrer a práticas negativas agressivas quando não sabem como agir diferente nessas situações, como, por exemplo, solicitar mudança de comportamento, expressar sentimento negativo de forma calma, dizer não com explicar, descrever efeitos do comportamento da criança. 
Importante destacar como afirma Goldiamond (2002) que todo comportamento tem uma função para o repertório da pessoa, então se a criança é agressiva ela o é porque dessa forma obtém atenção e/ou resolve problemas. O mesmo ocorre quanto ao professor que se recorre a práticas negativas de educação é porque existem certos comportamentos que realmente 0 aborrecem a ponto de não conseguirem se controlar. A de se destacar que as condições de trabalho podem prejudicar e/ou favorecer a manutenção das práticas negativas dos professores. Como afirma Oliveira (2005) a escola pode ser um ambiente que gera tensões e sofrimento. Dessa forma os problemas enfrentados pelo professor podem influenciar negativamente a forma como interage com seus alunos.

Na pesquisa de Del Prette e Del Prette (2009) com uma amostra de uma escola pública, os professores relataram acontecimentos de conflitos interpessoais semanais (ameaça, xingamentos, agressões físicas, gritos e discussões) entre os alunos e, ainda, registro de ocorrências diárias, em mediana, de 5 a 6 alunos agressivos, o que acarretou pouca efetividade no manejo dessas situações, concordando com os achados da presente pesquisa. Nota-se a dificuldade dos professores em lidar com interações de desobediência dos alunos, principalmente com aqueles que apresentam alta frequência de comportamentos opositores, assim como com os que possuem déficits de habilidades sociais. No que se refere à prática educativa do professor, conclui-se que os resultados atestam o que a literatura (Abreu \& Mazzetto, 1990; Andrade, 1990; Freire, 1996; Kullok, 2002) aponta acerca da importância do professor apresentar uma comunicação positiva (Fonseca, 2012; Howie, Lukacs, Pastor, Reuben, \& Mendo-la, 2010; Uysal \& Ergenekon, 2010), no estabelecimento de regras (Gomes, 2003), no manejo positivo (Webster--Stratton et al., 2008) e no valer-se do afeto (Kullok, 2002; Ribeiro, 2010) para estabelecer limites, promovendo, assim, as habilidades sociais infantis, o bom desempenho acadêmico e reduzindo a probabilidade de comportamentos problema.

Quanto às habilidades sociais infantis, nota-se que, segundo os relatos das professoras, as crianças de ambos os grupos mostraramse ser habilidosas, no entanto, o grupo não clínico demonstrou ter maior grau de assertividade e expressividade emocional, concordando com estudos que afirmam que a criança habilidosa tem menos comportamentos problema (Bandeira \& Quaglia, 2006; Bolsoni-Silva et al., 2013).

Pelos resultados conclui-se também que as crianças com problemas de comportamento também apresentam habilidades sociais, bem com as crianças habilidosas, ainda que com baixa frequência, também desobedecem e agridem, tal como já verificado por Bolsoni-Silva et al. (2006). Portanto, todas as crianças apresentam comportamentos habilidosos e não habilidosos, para os quais precisam de incentivo 
e/ou de limites. Os professores quando estabelecem limites de maneira clara, não agressiva e são capazes de serem comunicativos e afetivos, conseguem boa convivência e ensino adequado em sala de aula. As professoras deste estudo demonstram saber serem boas educadoras, no entanto, com as crianças que desobedecem muito parecem ter dificuldade de aplicar o que já sabem fazer com as crianças mais habilidosas, sugerindo a necessidade de orientação para lidar com essas crianças. Dessa forma, concorda-se com Patterson, Reid e Dishion (2000) que afirmam que os problemas de comportamento são aprendidos com os adultos de sua convivência, os quais, muitas vezes, são modelo e modelam comportamentos autoritários.

Um dos resultados apontados nessa pesquisa é o de que o professor manifesta atenção e conversa com 0 aluno do grupo clínico principalmente diante do repertório problema (apontando para o comportamento inadequado), pois a variável contexto é maior para - Grupo não clínico, que reflete a variabilidade de situações em que há interações positivas (assuntos diversos). Então, mantém-se forte o problema de comportamento, porque parece haver inconsistência na forma como a professora interage com essas crianças e também porque as crianças conseguem atenção nesses momentos, sem a obterem em outros momentos, por exemplo, quando são habilidosas. Como afirmam Patterson, Reid e Dishion (2002), no que se refere a problemas externalizantes, e Dozois e Dobson (2004), quanto à internalizantes, quando dificuldades socioemocionais não são trabalhadas no início do Ensino Fundamental podem levar a trajetórias no desenvolvimento negativas, aumentando a chance de a criança apresentar ao longo da vida escolar mais dificuldades tanto acadêmicas quanto interpessoais.

Concorda-se com Webster-Stratton et al. (2008) que propuseram, para as questões de ordem comportamental, incluir no currículo escolar conteúdos sociais e emocionais, propiciando aos professores habilidades eficazes em sala de aula. Conclui-se como necessário o trabalho efetivo do professor que use, sobretudo, práticas positivas para ensinar seus alunos, sejam as habilidades acadêmicas, sejam as interpessoais, o que pode favorecer o aumento das habilidades sociais das crianças e reduzir os problemas de comportamento (Webster-Stratton et al., 2008).

\section{Considerações finais}

Os resultados deste estudo apontam para várias implicações práticas, entre elas a prevenção de problemas de comportamento no contexto escolar, promoção do desenvolvimento da criança e importância e aquisição das habilidades sociais na vida escolar. O estudo acrescenta 
muito à literatura porque avalia todos esses comportamentos na interação social estabelecida entre professor e aluno, enfatizando as influências mútuas entre professor-aluno e não de cada um separadamente. Outra contribuição é ser um estudo comparativo a partir de identificação clínica dos alunos, ou seja, utilizou-se como critério para compor os grupos um instrumento com boas propriedades psicométricas, respondido pelas professoras, e não apenas a indicação verbal do professor.

Avaliar e identificar as práticas educativas dos profissionais da educação é um caminho para saber o que realmente acontece neste cenário, pois, muitas vezes, os docentes podem, inadvertidamente, estimular tais comportamentos, seja com modelos de agressividade ou deixando de perceber e incentivar comportamentos habilidosos dos seus alunos. Futuras pesquisas poderiam ampliar a amostra considerando as diferentes idades do Ensino Fundamental e também da Educação Infantil, além de associar outras medidas de coleta de dados, como a observação direta ou medidas de relatos dos próprios alunos.

\section{Referências}

Abreu, M. C., \& Mazzetto, M. T. (1990). O professor universitário em aula. São Paulo: MG Editores Associados.

Achenbach, T. M., \& Rescorla, L. A. (2001). Manual for the ASEBA School-Age Forms \& Profiles. Burlington, VT: University of Vermont, Research Center for Children, Youth, \& Families.

Allen, B. Sarah J., \& Backston, A. R. (2003). Training Preservice Teachers en collaborative problem salving: An investigation of the impact on teacher and student behavior change in realiworld settings. Shool Psychology Quartely, 18(1), 22-51.

Andrade, A. S. (1990). Condições de vida, potencial cognitivo e escola: um estudo etnográfico sobre alunos repetentes da $1^{\text {a }}$ série do $1^{\circ} \mathrm{grau}$. Cadernos de Pesquisa, (73), 26-37.

Bandeira, M., \& Quaglia, M. A. C. (2006). Comportamento assertivo: relações com ansiedade, lócus de controle e autoestima. In M. Bandeira, Z. A. P. Del Prette, \& A. Del Prette (Orgs.). Estudos sobre habilidades sociais e relacionamento interpessoal (pp. 1746). São Paulo: Casa do Psicólogo.

Bandeira, M., Rocha, S. S. Souza, T.M. P., Del Prette,Z. A. P., \& Del Prette, A. (2006). Comportamentos problemáticos em estudantes do ensino fundamental: características da ocorrência e relação com habilidades sociais e dificuldades de aprendizagem. Estudos de Psicologia, 11(2), 199-208.

Bardin, L. (2009). Análise de conteúdo. Lisboa: Edições 70. 
Baker, J. A., Grant, S., \& Morlock, L. (2008). The Teacher-Student Relationship as a Developmental Context for Children With Internalizing or Externalizing Behavior. School Psychology Quarterly, 23(1), 3-15.

Barnett, D. W., Bauer, A. M., Ehrhardt, K. E., Lentz, F. E., \&. Stollar, S. A. (1996). Keystone Targets for Change: Planning For Widespread Positive Consequences. School Psychology Quarterly $11(2)$, 95-117.

Bolsoni-Silva, A. T. (2002) Habilidades sociais: breve análise da teoria e da prática da luz do comportamento. Interação em Psicologia, 6(2), p.233-242.

Bolsoni-Silva, A. T., Marturano, E. M., Figueiredo, V. A. P., \& Manfrinato, J. W. S. (2006). Habilidades sociais e problemas de comportamento de pré-escolares: Comparando avaliações de mães e de professoras. Psicologia: Reflexão e Crítica, 19(3), 460-469.

Bolsoni-Silva, A. T., \& Carrara, K. (2010). Habilidades Sociais e Análise do Comportamento: compatibilidades e dissensões conceitual-metodológicas. Psicologia em Revista, 16, 330-350.

Bolsoni-Silva, A. T., Marturano, E. M., \& Freiria, L. R. B. (2010). Indicativos de Problemas de Comportamento e de Habilidades Sociais em Crianças: Um Estudo Longitudinal. Psicologia: Reflexão e Crítica, 23(3), 506-515.

Bolsoni-Silva, A. T., \& Loureiro, S. R. (2011). Validação do roteiro de entrevistas de habilidades sociais educativas (RE-HSE-P). Avaliação Psicológica, 9(1), 63-75.

Bolsoni-Silva, A. T., Loureiro, S. R., \& Marturano, E. (2011) Validação do questionário de respostas socialmente habilidosas versão para professores - QRSH-Pr. The Spanish Journal of Psychology.

Bolsoni-Silva, A. T., Mariano, M. L., Loureiro, S. R., \& Bonaccorsi, C. (2013). Contexto escolar: práticas educativas do professor, comportamento e habilidades sociais infantis. Revista Semestral da Associação Brasileira de Psicologia Escolar e Educacional, $17(2), 259-269$.

Castro, A. B., \& Bolsoni-Silva, A. T. (2008). Habilidades sociais na educação: relação entre concepções e práticas docentes na educação infantil. In V. L. M. F. Capellini, \& R. M. Manzoni (Orgs.). Políticas públicas, práticas pedagógicas e ensino aprendizagens: diferentes olhares sobre o processo educacional (pp. 296-311). São Paulo: Cultura Acadêmica.

Del Prette, Z. A. P. \& Del Prette, A. (1999). Psicologia das habilidades sociais: terapia e educação. Petrópolis, RJ: Vozes.

Del Prette, Z. A. P. \& Del Prette, A. (2001). Habilidades sociais e educação: pesquisa e atuação em psicologia escolar/ educacional. Em Z. A. P. Del Prette (Org.). Psicologia escolar e 
educacional: saúde e qualidade de vida (p.113-141). Campinas, SP: Alínea.

Del Prette, Z. A. \& Del Prette, A. (2009). Psicologia das habilidades sociais na infância: teoria e prática. $4^{a}$ Ed. Petrópolis, RJ: Vozes.

Dozois, J. A., \& Dobson, K. S. (2004). The prevention of anxiety and depression. Theory, research and practice. American Psychological Association: Washington.

Freire, P. (1996). Pedagogia da autonomia: saberes necessários à prática educativa. São Paulo: Paz e Terra.

Fonseca, B. C. R. (2012). Práticas educativas de genitores e professoras e repertório comportamental de crianças do ensino fundamental: Estudo de caso. Dissertação de Mestrado. Universidade Estadual Paulista. Faculdade de Ciências, Bauru, SP.

Greene, R. W., \& Ollendick, T. H. (1993). Evaluation of a multidimensional program for sixth-grader in transition from elementary to middle school. Journal of Community Psychology, 21,162-176.

Gomes, M. A. M. A. (2003). A utilização dos jogos na educação: diferentes abordagens. Psicologia Argumento, (10), 117-129.

Goldiamond, I. (2002). Toward a constructional approach to social problems: ethical and constitucional issues raised by applied behavior analysis. Behavior and social issues, 11, 108-197 (originalmente publicado em 1974).

Howie, L. D., Lukacs, S. L., Pastor, P. N., Reuben, C. A., \& Mendola, P. (2010). Participation in activities outside of school hours in relation to problem behavior and social skills in middle childhood. Journal Health Schandinavian, 80(3), 119-125.

Kullok, M. G. B. (2002). Relação Professor-Aluno: contribuições à prática pedagógica. Maceió: INEP.

Marturano, E. M. (2008). Tensões cotidianas da primeira série: um enfoque de desenvolvimento. Psicologia em Estudo, 13(1), 7987.

Oliveira, E. T. A., \& Wechsler, S. M. (2002) Variáveis que afetam a aprendizagem: percepção de alunos de licenciatura e professores. Psicologia Escolar e Educacional, 6(2), 133-139.

Oliveira, D. A. (2005). A reestruturação do trabalho docente: precarização e flexibilização. Educação e Sociedade, 26 (92), 753-775.

Patterson, G., Reid, J., \& Dishion, T. (2002). Antisocial boys. Comportamento anti-social. Santo André, SP: ESETec.

Pereira, M. T., Marturano, E. M., Gardinal-Pizato, E. C., \& Fontaine, A. M. G. (2011). Possíveis contribuições da educação infantil para o desempenho e a competência social de escolares. Revista Semestral da Associação Brasileira de Psicologia Escolar e 
Educacional, 15 (1), 101-109.

Ribeiro, M. L. (2010). A afetividade na relação educativa. Estudos de Psicologia (Campinas), 27(3), 403-412.

Uysal, A., \& Ergenekon, Y. (2010). Social skills instruction carried out by teachers working at private special education institutions in Turkey. Education and training in autism and developmental disabilities, 45(3), 459-466.

Webster-Stratton, C., Reid, J., \& Stoolmiller, M. (2008). Preventing conduct problems and improving school readiness: evaluation of the Incredible Years Teacher and Child Training Programs in high-risk schools. Journal of Child Psychology and Psychiatry, 49(5), 471-488.

\section{Endereço para correspondência}

\section{Alessandra Turini Bolsoni-Silva}

Universidade Estadual Paulista

Faculdade de Ciências - UNESP - Campus de Bauru

Av. Eng. Luiz Edmundo Carrijo Coube, 14-01 - Vargem Limpa, CEP 17033-360, Bauru - SP, Brasil

Endereço eletrônico: bolsoni@fc.unesp.br

\section{Maria Luiza Mariano}

Universidade Estadual Paulista

Faculdade de Ciências - UNESP - Campus de Bauru

Av. Eng. Luiz Edmundo Carrijo Coube, 14-01 - Vargem Limpa, CEP 17033-360, Bauru - SP, Brasil

Endereço eletrônico: maluizamariano@yahoo.com.br

Recebido em: 21/05/2014

Reformulado em: 29/10/2014

Aceito para publicação: 29/10/2014

\section{Notas}

* Livre-Docente em Psicologia Clínica (Unesp)

** Mestre em Psicologia do Desenvolvimento e Aprendizagem (Unesp) 